University of Nebraska - Lincoln

DigitalCommons@University of Nebraska - Lincoln

Impaired receptor-mediated endocytosis by the asialoglycoprotein receptor in ethanol-fed mice: implications for studying the role of this receptor in alcoholic apoptosis

\author{
Shana R. Dalton \\ University qf Nebraska Medical Center, Omaha, NE \\ Robert L. Wiegert \\ University qf Nebraska Medical Center, Omaha, NE \\ Cheryl R. Baldwin \\ University qf Nebraska Medical Center, Omaha, NE \\ Karen M. Kassel \\ University qf Nebraska Medical Center, Omaha, NE \\ Carol A. Casey \\ University of Nebraska Medical Center, ccasey@unmc.edu
}

Follow this and additional works at: https://digitalcommons.unl.edu/publichealthresources

Part of the Public Health Commons

Dalton, Shana R.; Wiegert, Robert L.; Baldwin, Cheryl R.; Kassel, Karen M.; and Casey, Carol A., "Impaired receptor-mediated endocytosis by the asialoglycoprotein receptor in ethanol-fed mice: implications for studying the role of this receptor in alcoholic apoptosis" (2003). Public Health Resources. 52.

https://digitalcommons.unl.edu/publichealthresources/52

This Article is brought to you for free and open access by the Public Health Resources at DigitalCommons@University of Nebraska - Lincoln. It has been accepted for inclusion in Public Health Resources by an authorized administrator of DigitalCommons@University of Nebraska - Lincoln. 


\title{
Impaired receptor-mediated endocytosis by the asialoglycoprotein receptor in ethanol-fed mice: implications for studying the role of this receptor in alcoholic apoptosis
}

\author{
Shana R. Dalton ${ }^{\mathrm{a}, \mathrm{b}}$, Robert L. Wiegert ${ }^{\mathrm{a}}$, Cheryl R. Baldwin ${ }^{\mathrm{a}}$, \\ Karen M. Kassel ${ }^{\mathrm{a}}$, Carol A. Casey ${ }^{\mathrm{a}, \mathrm{c}, \mathrm{d}, *}$ \\ ${ }^{a}$ Department of Internal Medicine, University of Nebraska Medical Center, Omaha, NE 68198-2000, USA \\ ${ }^{\mathrm{b}}$ Department of Pathology \& Microbiology, University of Nebraska Medical Center, Omaha, NE 68198-3135, USA \\ ${ }^{c}$ Department of Biochemistry \& Molecular Biology, University of Nebraska Medical Center, Omaha, NE 68198-4525, USA \\ ${ }^{\mathrm{d}}$ Liver Study Unit, Department of Veterans Affairs Medical Center, Research (151), 4101 Woolworth Ave., Omaha, NE 68105, USA
}

Received 28 February 2002; accepted 23 July 2002

\begin{abstract}
During receptor-mediated endocytosis (RME), extracellular molecules are internalized after being recognized and bound to specific cell surface receptors. In previous studies of the asialoglycoprotein receptor (ASGPR) in rats, we showed that ethanol impairs RME at multiple ASGPR sites. Ethanol administration has been shown to increase apoptosis, and we demonstrated increased sensitization to apoptotic induction in hepatocytes from ethanol-fed rats. Although a physiological role for the ASGPR has not been identified, investigators have shown its involvement in the uptake/clearance of apoptotic cells in vitro. This suggests a potential role for the ASGPR in the removal of apoptotic cells, and the recent availability of an ASGPR-deficient mouse strain provides an excellent opportunity to examine the role of the ASGPR during ethanol impairment. In this study, we examined ethanol-impaired RME in mice and began the characterization of ASGPR-deficient mice for use in ethanol studies. Similar to our findings with rats, ligand binding, internalization, and degradation were decreased $45-50 \%$ in hepatocytes from ethanol-fed wild-type mice. In ASGPR-deficient mice, these parameters did not vary among the chow-fed, pair-fed control, or ethanol groups and were negligible compared with those of wild-type mice. TUNEL analysis of liver sections showed an ethanol-induced increase in apoptotic bodies in all mouse strains with a significant difference in the receptor-deficient mice. Further, the livers of ASGPR-deficient mice had three times more apoptotic bodies, in all feeding groups, compared with wild-type mice. These results support the use of the ASGPR-deficient mouse model for studying ethanol-induced liver injury, specifically ethanol-induced apoptosis.
\end{abstract}

Keywords: Receptor-mediated endocytosis; Apoptosis; Ethanol; Asialoglycoprotein receptor; Asialoglycoprotein receptor-deficient mouse; TUNEL

\section{Introduction}

Ethanol abuse is a major health concern in the United States, and it has been well established that chronic

\footnotetext{
${ }^{*}$ Corresponding author. Tel.: +1-402-346-8800 Ext. 3737; fax: +1-402-449-0604.

E-mail address: ccasey@unmc.edu (C.A. Casey).

Abbreviations: RME, receptor-mediated endocytosis; ASGPR, asialoglycoprotein receptor; ASOR, asialoorosomucoid; PTA, phosphotungstic acid; TCA, trichloroacetic acid; TdT, terminal deoxynucleotidyltransferase; TUNEL, TdT-mediated dUTP nick-end labeling; $1 \times$ SSC, $0.15 \mathrm{M}$ sodium chloride- $0.015 \mathrm{M}$ sodium citrate, $\mathrm{pH} 7.2$; BCA, bicinchoninic acid; and LPS, lipopolysaccharide.
}

exposure to ethanol can result in liver disease. Although research in this area has been extensive, the mechanism(s) of ethanol-induced liver injury remains unclear. Previous research from our laboratory has examined the effects of both acute and chronic ethanol exposure on liver cell function, particularly as it relates to altered protein trafficking in the process of RME [1-4]. RME is the process whereby specific molecules in extracellular fluid are recognized and bound by cell surface receptors, then internalized in vesicles for further processing inside the cell [5]. We have used the hepatocyte-specific ASGPR as a model for studying the effects of ethanol on RME and, in rats, have identified multiple steps in the process that are altered upon 
exposure to ethanol. These alterations include decreased binding, internalization, and degradation of ASOR, a ligand for the ASGPR, as well as altered receptor-ligand uncoupling and endosomal acidification [3,4,6-10].

Another aspect of ethanol exposure is an increase in the apoptosis of hepatocytes [11,12]. Apoptosis is a normal, active process of cell death that results in the rapid removal of damaged or unwanted cells and, unlike necrosis, this removal is accomplished without inducing damage to the surrounding tissue. However, an increase in the level of apoptotic bodies has the potential to overwhelm their timely removal, which could result in damage to the surrounding tissue. One interesting aspect of apoptotic cells is an increase in the number of glycoconjugates, normally masked by sialic acid moieties, which are present on the cell surface [13-16]. Since the ASGPR binds proteins that have lost their terminal sialic acid moieties and have exposed galactose or $N$-acetylgalactose amine moieties [16,17], a potential role is suggested for the ASGPR in the clearance of apoptotic bodies from the liver. Indeed, Dini and colleagues [16,18] have presented evidence to support such a role for the ASGPR. In their in vitro experiments, various inhibitors of the ASGPR blocked the uptake of apoptotic bodies. Recently, our laboratory has begun to investigate the potential role of the ASGPR in the clearance of apoptotic bodies. We have shown that hepatocytes isolated from ethanol-treated rats are more susceptible to apoptotic induction by various agents and, irrespective of experimental conditions, in the presence of saturating levels of ligand for the ASGPR the incidence of apoptotic nuclei increases in hepatocytes from both control and ethanol-fed rats [19]. The possibility that the ASGPR is involved in removing cells undergoing apoptosis indicates a new perspective in the functional consequences of ethanol-induced impairments in ASGPR function. Recently, an ASGPR-deficient mouse strain has become available that may provide an excellent opportunity to examine the role of the ASGPR in apoptosis and the effects of ethanol on this system.

Although the receptor-deficient mice are phenotypically similar to the wild-type mice, no data are available on how they respond to ethanol administration. Since all of our observations regarding the effects of ethanol on RME have been made in rats, we first needed to establish that these effects are also seen in mice. The purpose of the research presented in this paper was 2-fold: first, to assess the effects of ethanol on RME in a mouse model, and second, to begin determining the potential of the ASGPR-deficient mouse model for studying the role of the receptor in ethanolinduced apoptosis. To accomplish this, we determined binding, internalization, and degradation of ASOR in hepatocytes isolated from several different mouse strains: C57BL/6; 129SV; B6,129S, a crossbreed of the C57BL/6 and 129SV strains; and the ASGPR-deficient strain, available from both the 129SV and crossbred backgrounds. C57BL/6 mice are commonly used for ethanol studies as they will drink the ethanol diet ad lib. We also looked at the effects of ethanol on hepatic apoptosis in vivo in the various mouse strains using the TUNEL assay.

\section{Materials and methods}

\subsection{Materials}

Sigma was the source of human orosomucoid $\left(\alpha_{1}\right.$-acid glycoprotein), EDTA, Percoll, propidium iodide, PTA, sucrose, and TCA. Superfrost/Plus slides, glass coverslips, and the tissue freezing medium were purchased from Fisher Scientific. $\mathrm{Na}^{125}$ I was obtained from Amersham-Pharmacia. DNase I and Liberase Blendzyme 3 were obtained from Roche Molecular Biochemicals. Mediatech, Inc. was the source of the Eagle's medium and fetal bovine serum. Vectashield was purchased from Vector Laboratories. The TUNEL kit was obtained from Promega and the BCA Protein Assay Kit from Pierce. The Intergen Co. was the source of BSA, and paraformaldehyde (16\%) was purchased from Electron Microscope Sciences. All reagents not specifically identified were obtained from commercially available sources.

The C57BL/6 mice were obtained from the National Cancer Institute. Jackson Laboratories was the source of mice from the $129 \mathrm{SV}$ and the B6,129S strains. The ASGPR-deficient mice from both the 129SV and crossbred backgrounds (B6,129S-Asgpr2) were also obtained from Jackson Laboratories. All animals were maintained on Purina rodent chow until used for experiments.

Nutritionally adequate Lieber-DeCarli high protein liquid diets were obtained from Dyets, Inc. The caloric distribution in the ethanol diet was as follows: $27 \%$ as carbohydrate, $25 \%$ as protein, $12 \%$ as fat, and $36 \%$ as ethanol. The control diet was isocaloric to the ethanol diet with the ethanol portion accounted for by additional carbohydrates. Desialyation and iodination of the human orosomucoid was accomplished by the method of Oka and Weigel [20], as previously described [6].

\subsection{Ethanol administration}

The experimental groups were ad lib. chow-fed and ethanol-fed and pair-fed control. The pair-fed mice $(\geq 22 \mathrm{~g})$ were housed individually and acclimated to the control Lieber-DeCarli liquid diet for 1 day. The mice were then paired according to weight, and one member of the pair was maintained on the control liquid diet. The other member of the pair was gradually introduced to the ethanol liquid diet in daily increments by increasing the level of ethanol from 12 to $24 \%$ to the final $36 \%$ of total calories. The pair-feeding protocol was then maintained for an additional 7 days. The animals were handled and housed according to the guidelines of the American Association for Accreditation of the Laboratory Animal Care-Approved Animal Research Facility at the Omaha 
Veterans Affairs Medical Center and the studies approved by the Animal Studies Subcommittee of the Omaha Veterans Affairs Medical Center.

\subsection{Hepatocyte isolation}

Hepatocytes were obtained using a collagenase perfusion method that is routinely performed in our laboratory [6]. For the collagenase perfusion, we used Liberase Blendzyme 3, a mixture of highly purified collagenase (types I and II) and the neutral protease enzyme, thermolysin, at a concentration of $2.5 \mu \mathrm{g} / \mathrm{mL}$ in Krebs-Ringers, $\mathrm{pH} 7.4$, with $2.5 \mathrm{mM} \mathrm{Ca}^{2+}$. Percoll gradients (25-30\%, $\mathrm{v} / \mathrm{v})$ were used to further purify isolated hepatocytes such that viability of the cells used in the assays was $85-95 \%$, assessed with trypan blue exclusion. Isolated hepatocytes were preincubated in Krebs-Ringers, $\mathrm{pH} 7.4$, with $2.5 \mathrm{mM}$ $\mathrm{Ca}^{2+}$ and $2 \%$ BSA $\left(37^{\circ}, 30 \mathrm{~min}\right)$ before use in the ${ }^{125}$ I-ASOR binding and internalization/degradation assays.

\section{4. ${ }^{125}$ I-ASOR binding}

Isolated hepatocytes from chow-fed and pair-fed mice were suspended in Eagle's medium, pH 7.4, with $10 \mathrm{mM}$ HEPES and $0.5 \%$ BSA at a concentration of $1-2 \times 10^{6}$ cells/ $\mathrm{mL} .{ }^{125} \mathrm{I}-\mathrm{ASOR}$ at a final concentration of $1.0 \mu \mathrm{g} / \mathrm{mL}$ was added to $1-\mathrm{mL}$ aliquots of the cell suspension and incubated $\left(4^{\circ}, 60 \mathrm{~min}\right)$ with gentle swirling. After incubation, the cells were washed with Krebs-Ringers, $\mathrm{pH} 7.4$, with $2.5 \mathrm{mM}$ $\mathrm{Ca}^{2+}$ to remove unbound ligand, and the radioactivity in the cell pellets was determined. Non-specific binding was determined by adding a 100-fold excess of unlabeled ligand or EDTA to a final concentration of $20 \mathrm{mM}$ EDTA. Results obtained from both treatments were similar and showed that non-specific binding was $<10 \%$ of specific binding.

\section{5. ${ }^{125}$ I-ASOR internalization and degradation}

Mouse hepatocytes were suspended in Eagle's medium, pH 7.4, with $10 \mathrm{mM}$ HEPES and $0.5 \%$ BSA at a concentration of $2 \times 10^{6}$ cells $/ \mathrm{mL}$. ${ }^{125} \mathrm{I}$-ASOR at a final concentration of $2.5 \mu \mathrm{g} / \mathrm{mL}$ was added to the cell suspension, and the cell suspension was incubated at $37^{\circ}$ with gentle swirling. At $0,30,60,90,105,120,135$, and $150 \mathrm{~min}$ an aliquot was removed to ice-cold Krebs-Ringers, $\mathrm{pH} 7.4$, with $25 \mathrm{mM}$ EDTA and incubated on ice to remove surface-bound ligand. After a minimum of $10 \mathrm{~min}$ on ice, the cells were pelleted $\left(900 \mathrm{~g}, 4^{\circ}, 3 \mathrm{~min}\right)$, and an aliquot of the supernatant was placed in an equal volume of ice-cold $20 \%$ TCA $/ 2 \%$ PTA and incubated for a minimum of $10 \mathrm{~min}$ on ice. The cell pellet was washed in Krebs-Ringers, $\mathrm{pH} 7.4$, and the radioactivity in the cell pellet determined $\left({ }^{125} \mathrm{I}-\right.$ ASOR internalization). The TCA/PTA mixture was centrifuged $\left(900 \mathrm{~g}, 4^{\circ}, 10 \mathrm{~min}\right)$, and the radioactivity of an aliquot of the resulting supernatant was determined $\left({ }^{125} \mathrm{I}-\right.$ ASOR degradation).

\subsection{TUNEL analysis}

Liver tissue was fixed using a procedure described by Van Dyke [21]. Briefly, livers of chow-fed and pair-fed mice were perfused with cold $4 \%$ paraformaldehyde for $10 \mathrm{~min}$ prior to removal. Then the livers were cut into 7 - to 8 -mm squares, further fixed in cold $4 \%$ paraformaldehyde $\left(3 \mathrm{hr}\right.$ ), and incubated at $4^{\circ}$ in increasing molarities of sucrose/PBS solutions made from 5 and 20\% sucrose/ PBS stock solutions. Tissue was swirled often and floating pieces were discarded. The liver pieces were placed in a 2:1 mixture of $20 \%$ sucrose/PBS and tissue freezing medium (TFM) (30 min, room temperature). Individual liver pieces were placed in trays containing $20 \%$ sucrose/PBS:TFM (2:1) and frozen in isopentane cooled by liquid nitrogen. Liver sections were cut $(5 \mu \mathrm{m})$, placed on Superfrost/Plus microscope slides, and processed according to the procedure provided with the TUNEL kit (Promega). Briefly, tissue was fixed on the slides in $4 \%$ paraformaldehyde $\left(25 \mathrm{~min}, 4^{\circ}\right)$ and then permeabilized in $0.1 \%$ Triton X-100 $\left(10 \mathrm{~min}, 4^{\circ}\right)$. The liver sections were covered with TdT incubation buffer (TUNEL kit) and incubated in a dark humid chamber $\left(37^{\circ}, 1 \mathrm{hr}\right)$. Positive controls were treated with DNase I buffer containing $0.25 \mu \mathrm{g} / \mathrm{mL}$ of DNase I (10 min, room temperature) prior to incubation, and negative controls were incubated in TdT incubation buffer without the TdT enzyme. The slides were placed in $2 \times$ SSC (TUNEL kit; $15 \mathrm{~min}$, room temperature) to stop the reaction and then counter-stained in a propidium iodide solution $(1 \mu \mathrm{g} / \mathrm{mL} ; 15 \mathrm{~min}$, room temperature). A drop of Vectashield was placed over the liver section, a coverslip was added, and the edges were sealed with clear nail polish. TUNEL-stained sections were visualized with a fluorescence microscope (Nikon Optiphot), and an average of 5500 cells (total) per treatment group were counted to determine the percent apoptotic.

\subsection{General}

Protein was determined using the BCA Protein Assay Kit with BSA as a standard. ${ }^{125}$ I-Radioactivity was determined using an LKB gamma spectrometer. Cell number was determined using a hemocytometer. Statistical analyses were conducted using Student's $t$-test.

\section{Results}

\subsection{Surface binding of ${ }^{125}$ I-ASOR to mouse hepatocytes}

To determine if ethanol administration affects the ASGPR system of mice in a manner similar to that observed in rats, we examined the ability of ${ }^{125} \mathrm{I}$-ASOR to bind to the surface of hepatocytes isolated from male and female C57BL/6 mice. The data in Fig. 1 for male (Fig. 1A) and female (Fig. 1B) mice are presented as the femtomoles 


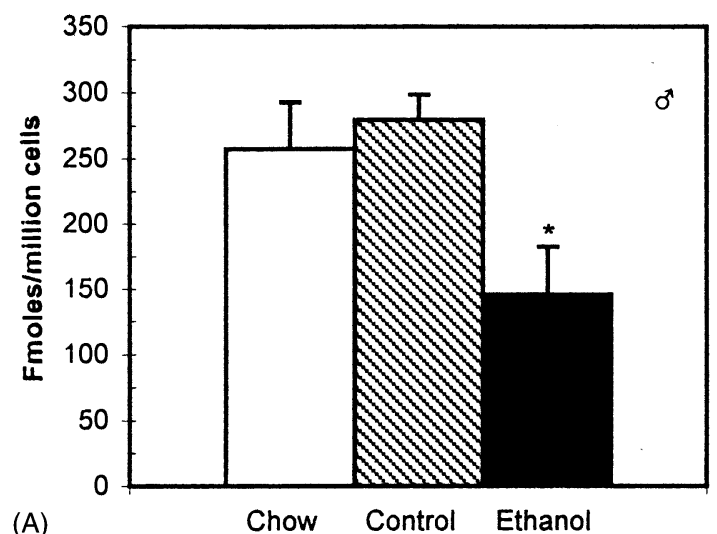

(A)

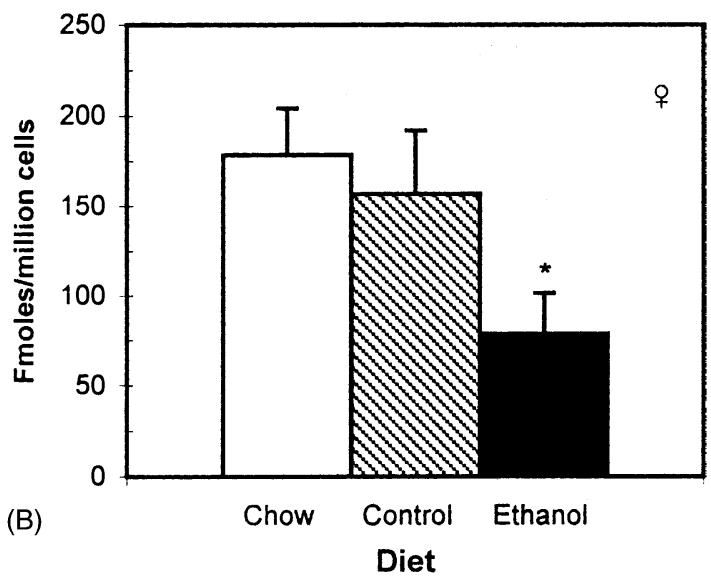

Fig. 1. Surface binding of ${ }^{125} \mathrm{I}$-ASOR to hepatocytes isolated from C57BL/6 mice. Isolated hepatocytes were obtained from male (A) and female (B) mice fed a chow diet or control or ethanol-containing liquid diet for 7 days. Binding of ${ }^{125}$ I-ASOR to surface receptors was determined as described in "Section 2." Data are presented as femtomoles bound per million cells and are means \pm SEM $\left(\mathrm{N}=4-6\right.$ experiments). Key: $\left(^{*}\right)$ statistically significant from chow and control groups at $P \leq 0.05$.

of ${ }^{125} \mathrm{I}$-ASOR bound per million cells. Although the binding of ${ }^{125} \mathrm{I}$-ASOR to hepatocytes isolated from male mice was elevated compared to the female counterparts, this increase was not significantly different and the pattern of binding was similar in hepatocytes from both males and females. Surface binding of ${ }^{125} \mathrm{I}$-ASOR to hepatocytes isolated from chow-fed and pair-fed controls was comparable, indicating that restricted access to diet does not affect ligand binding to the ASGPR significantly in this system. Hepatocytes isolated from ethanol-fed mice, however, demonstrated a decrease of approximately $45-50 \%$ in the surface binding of ${ }^{125} \mathrm{I}$-ASOR. The effects of ethanol on the surface binding of ${ }^{125} \mathrm{I}$-ASOR in the female mice from the other two ASGPR wild-type strains-129SV and B6,129S - were consistent with our observations made using C57BL/6 mice (data not shown). These results are also consistent with previous observations from our laboratory using hepatocytes isolated from ethanol-treated rats $[4,6,9] .{ }^{125}$ I-ASOR surface binding in hepatocytes isolated from female mice from the ASGPR-deficient mouse strain was approximately $10 \%$ of that observed in the wild-type mouse strains (data not shown).

\subsection{Internalization and degradation of ${ }^{125}$ I-ASOR by mouse hepatocytes}

In addition to surface binding, we investigated ligand internalization and degradation in isolated hepatocytes from both male and female C57BL/6 mice. Ligand internalization was determined as the amount of ${ }^{125}$ I-ASOR that remained associated with hepatocytes after EDTA displacement of any remaining surface-bound ligand, and degradation was assessed as the amount of soluble radioactivity present after precipitation of intact protein. The data presented in Figs. 2 and 3 show the results obtained using hepatocytes from male and female mice, respectively. The amount ${ }^{125}$ I-ASOR internalized by hepatocytes isolated from ethanol-fed mice was reduced significantly at all time points assayed (Figs. 2A and 3A). Further, ligand degradation was reduced significantly in hepatocytes from ethanolfed mice (Figs. 2B and 3B). Similar ethanol-induced alterations in internalization and degradation of ${ }^{125} \mathrm{I}$-ASOR were observed in the other two ASGPR wild-type mice strains (data not shown). Although there was no statistical difference, we observed elevated levels of ligand internalization and degradation in male mice compared to female mice. In our initial studies, two different preparations of ${ }^{125} \mathrm{I}$-ASOR were used to obtain the data presented in Figs. 2 and 3. Subsequent studies with hepatocytes isolated from B6,129S chow-fed male and female mice using a single preparation of ${ }^{125} \mathrm{I}$-ASOR showed comparable levels of internalization and degradation between the two sexes. The data obtained from these studies are combined and presented as the wild-type chow (WT-CW) group presented in Fig. 4. Internalization (Fig. 4A) and degradation (Fig. 4B) of ligand by hepatocytes isolated from chow-fed ASGPR-deficient mice was negligible to and significantly different from what was observed in the chow-fed wildtype mice at all time points tested. Internalization and degradation data were obtained for hepatocytes isolated from pair-fed control and ethanol ASGPR-deficient mice and are presented in panels A and B of Fig. 4 as inset graphs. The data were presented in this manner because the lines for all diet groups of the receptor-deficient mice overlapped and could not be distinguished from one another. As with hepatocytes from chow-fed ASGPRdeficient mice, ${ }^{125} \mathrm{I}$-ASOR internalization and degradation in the pair-fed mice were reduced significantly at all time points tested (significance not shown on graph insets). Our current findings that ligand internalization and degradation by the ASGPR in mice are impaired by exposure to ethanol are again consistent with our previous observations using ethanol-fed rats $[4,6,9]$.

\subsection{TUNEL analysis in liver sections from C57BL/6, 129SV, and ASGPR-deficient female mice}

As previously stated, ethanol administration has been shown to increase the number of apoptotic bodies present 

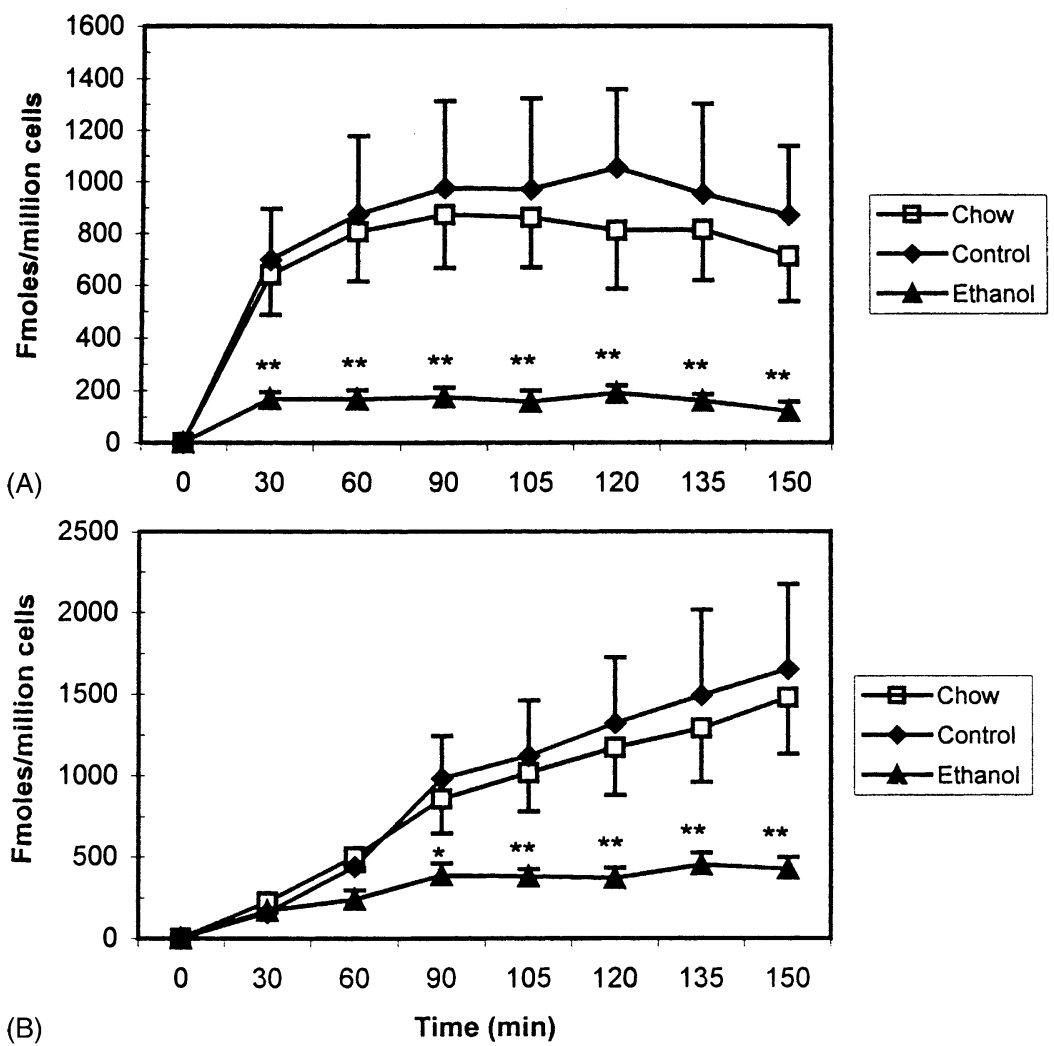

Fig. 2. Internalization and degradation of ${ }^{125} \mathrm{I}-\mathrm{ASOR}$ in hepatocytes isolated from C57BL/6 male mice. Isolated hepatocytes were obtained from mice fed a chow diet or control or ethanol-containing liquid diet for 7 days. Internalization (A) and degradation (B) of ${ }^{125}$ I-ASOR were determined as described in "Section 2." Data are presented as femtomoles bound per million cells and are means \pm SEM $(\mathrm{N}=3-6$ experiments). Statistically significant differences from chow and control groups are indicated as follows: $\left({ }^{*}\right)$ significance at $P \leq 0.05$, and $\left({ }^{* *}\right)$ significance at $P \leq 0.01$.

in liver [11,12]. We used the TUNEL assay on liver sections from chow-fed and pair-fed control and ethanol mice from the ASGPR wild-type strains, C57BL/6 and $129 \mathrm{SV}$, and the ASGPR-deficient strain. For all treatment groups, an average of 5500 cells were counted, and the resulting data are presented in Fig. 5 as the percent apoptotic. Within the mouse strains, the labeling indexes (percent apoptotic) of the chow-fed and pair-fed controls were comparable. Further, the labeling indexes of all the ethanol-treated mice were 1.5 to 2 times greater compared with the chow-fed and pair-fed controls (Fig. 5). For the ASGPR-deficient strain, this ethanol-induced increase was significantly different. A comparison between mouse strains shows that the labeling indexes for the C57BL/6 and $129 \mathrm{SV}$ mice were comparable in all three dietary groups (Fig. 5). However, the labeling indexes were three times greater in all of the dietary groups of the ASGPRdeficient mice compared with the other two mouse strains (Fig. 5).

\section{Discussion}

Extensive research within our laboratory has revealed a number of steps in the process of RME by the ASGPR that are affected by ethanol administration; however, all of these data were gathered using a rat model [3,4,6-10]. Although ethanol-induced alterations, including apoptosis [11], have been observed using mouse models, to our knowledge there have been no investigations of ethanol impairment of RME by the ASGPR using mice. To utilize the ASGPR-deficient mouse model for our investigations of ethanol-impaired receptor function, we first needed to establish that the effects of ethanol on the ASGPR system in mice paralleled our previous observations made with rats. Since the preponderance of work using mouse models is done with female mice, and our rat model used male rats, we also wanted to determine if the effects of ethanol on the ASGPR system were seen in both male and female mice. With our rat model, we consistently observed a decrease of approximately $50 \%$ in ligand binding, internalization, and degradation in hepatocytes isolated from ethanol-treated animals $[3,4,6,7]$. The results presented here using a mouse model to assess ethanol-induced alterations in RME are consistent with our observations made with rats. A similar pattern of ethanol-impaired RME, $\sim 50 \%$ of controls, was observed in both sexes of wild-type mice. In our initial studies, we observed elevated levels of endocytosis of ${ }^{125} \mathrm{I}$ ASOR by hepatocytes isolated from male mice, regardless of the feeding regime, compared with hepatocytes from female mice, although there was no statistical difference between the data obtained from the two sexes. During the 


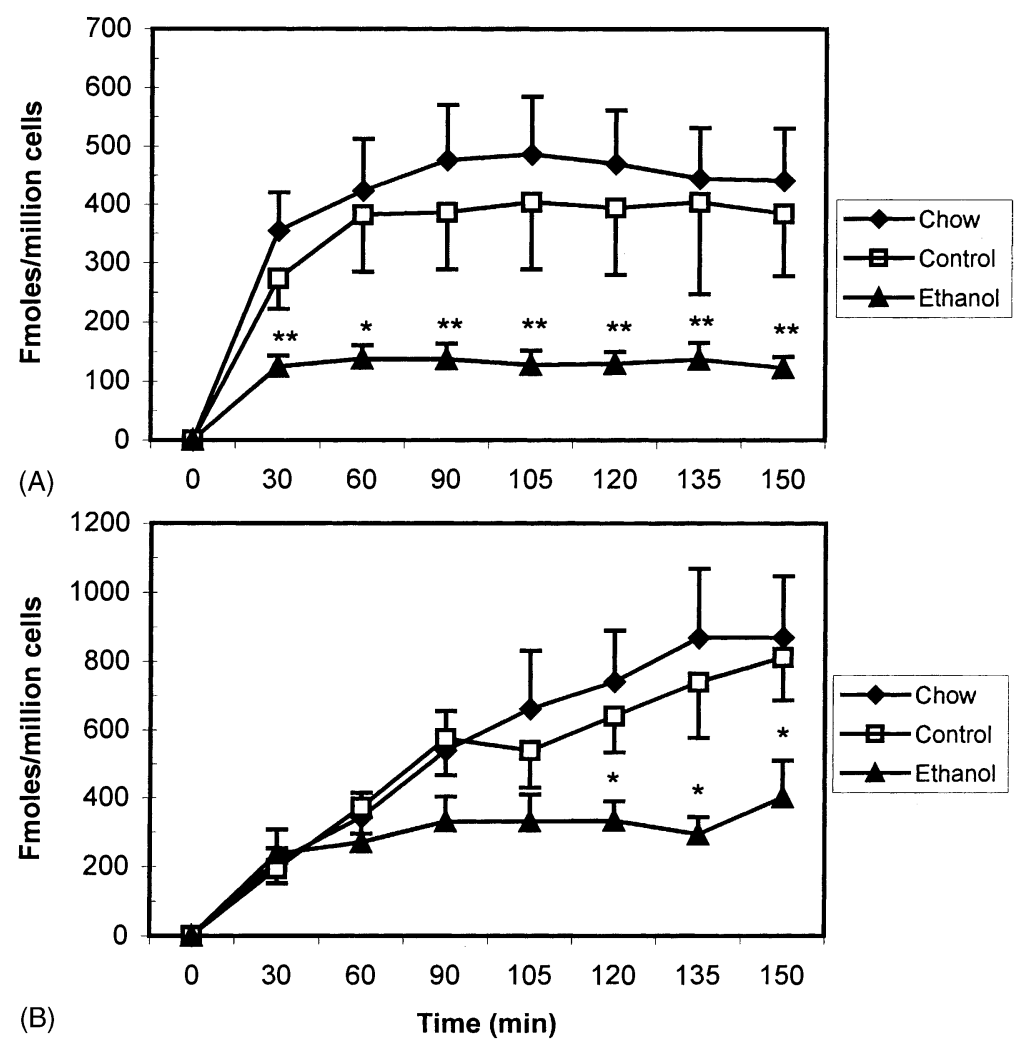

Fig. 3. Internalization and degradation of ${ }^{125} \mathrm{I}-\mathrm{ASOR}$ in hepatocytes isolated from female C57BL/6 mice. Hepatocytes were obtained from mice fed a chow diet or control or ethanol-containing liquid diet for 7 days. Internalization (A) and degradation (B) of ${ }^{125}$ I-ASOR were determined as described in "Section 2." Data are presented as femtomoles bound per million cells and are means \pm SEM $(\mathrm{N}=4-6$ experiments). Statistically significant differences from chow and control groups are indicated as follows: $\left(^{*}\right)$ significance at $P \leq 0.05$, and $\left(^{* *}\right)$ significance at $P \leq 0.01$.

course of the studies investigating endocytosis by the ASGPR, two preparations of ${ }^{125} \mathrm{I}-\mathrm{ASOR}$ were needed. The arrangement of the studies was such that the male studies were completed with most of one preparation, while the females were done primarily with the other. Because the specific activities of the two ${ }^{125}$ I-ASOR preparations were similar ( $\sim 64 \mathrm{cpm} / \mathrm{fmol}$ ASOR), we felt that the variability between the sexes resulted from differences in the specificity of the ligand preparations used for iodination. We addressed this question by conducting studies with male and female wild-type mice using a single preparation of ${ }^{125} \mathrm{I}$-ASOR and found no difference between the sexes. Further, the values were comparable to those obtained in the first male experiments. These findings support our belief that the different levels of ligand endocytosis by male and female mice observed in the first set of experiments resulted from variations in ligand specificity of the ASOR preparations used for the iodinations. As expected, binding, internalization, and degradation of ligand by hepatocytes isolated from ASGPR-deficient mice, irrespective of diet, was only a fraction of that observed in hepatocytes from wild-type mice. These results indicate that ethanol-induced alterations in RME can be observed using either a rat or mouse model; in addition, they demonstrate that RME by the ASGPR is negligible in the receptor-deficient mouse strain.
Ethanol-induced apoptosis has been well established, and its importance in alcohol-related liver disease is becoming clearer [11,12,22-24]. Although rapid removal of apoptotic bodies is important in preventing additional damage to surrounding tissue, the molecular mechanisms for the recognition and removal systems remain undetermined. One potential mechanism involves modification of the extracellular membrane of apoptotic cells resulting in the unmasking and/or presentation of specific markers that make the cells targets for removal. The combined observations of Savill's [13-15] and Dini's [16,18] groups with respect to increased glycoconjugate presentation on apoptotic cells and involvement of the ASGPR in their clearance suggest that functional ASGPRs may play a role in the clearance of apoptotic cells from the liver. If we include our observations of ethanol-impaired RME by the ASGPR, the result is a potential pathway to help explain the deleterious effects of chronic ethanol consumption. Our analysis of TUNEL-processed liver sections from ASGPR-deficient mice provides preliminary evidence to support this idea. Consistent with reports in the literature, we observed an increase in the number of apoptotic bodies present in the livers of ethanol-fed mice. Of particular importance was our observation that the labeling index (\% apoptotic) in the livers of all the dietary groups of the ASGPR-deficient mice was approximately three times greater then what was 

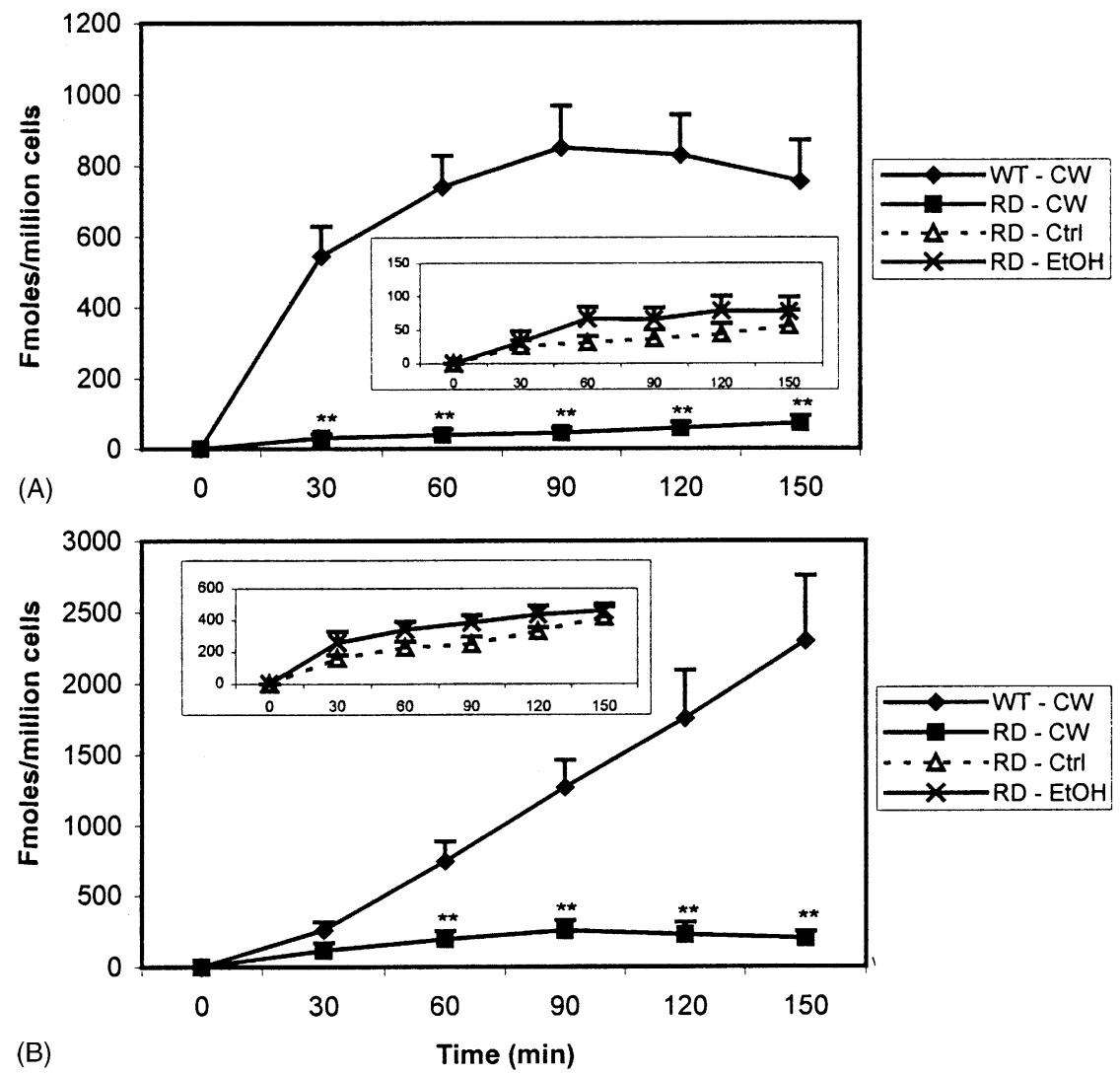

Fig. 4. Internalization and degradation of ${ }^{125} \mathrm{I}-\mathrm{ASOR}$ in hepatocytes isolated from B6,129S wild-type and ASGPR-deficient mice. Isolated hepatocytes were obtained from wild-type and receptor-deficient chow-fed mice and receptor-deficient mice fed a control or ethanol-containing liquid diet for 7 days. Internalization (A) and degradation (B) of ${ }^{125}$ I-ASOR were determined as described in "Section 2." Data are presented as femtomoles bound per million cells, main and inset graphs, and are means \pm SEM $(\mathrm{N}=4-5$ experiments $)$. Key: $\left(^{* *}\right)$ statistically significant from wild-type chow mice at $P \leq 0.01$.

observed in either of the wild-type mouse strains investigated. This finding supports the hypothesis that the ASGPR may play a role in the clearance of apoptotic bodies from liver tissue. A report by Deaciuc et al. [25] investigating the apoptotic effects of ethanol and LPS in mouse liver suggests that the effects of ethanol may provide a background that sensitizes the liver to other damaging agents such as LPS. This is consistent with our observation, using hepatocytes from ethanol-treated rats, of increased susceptibility to apoptotic induction by various agents [19].

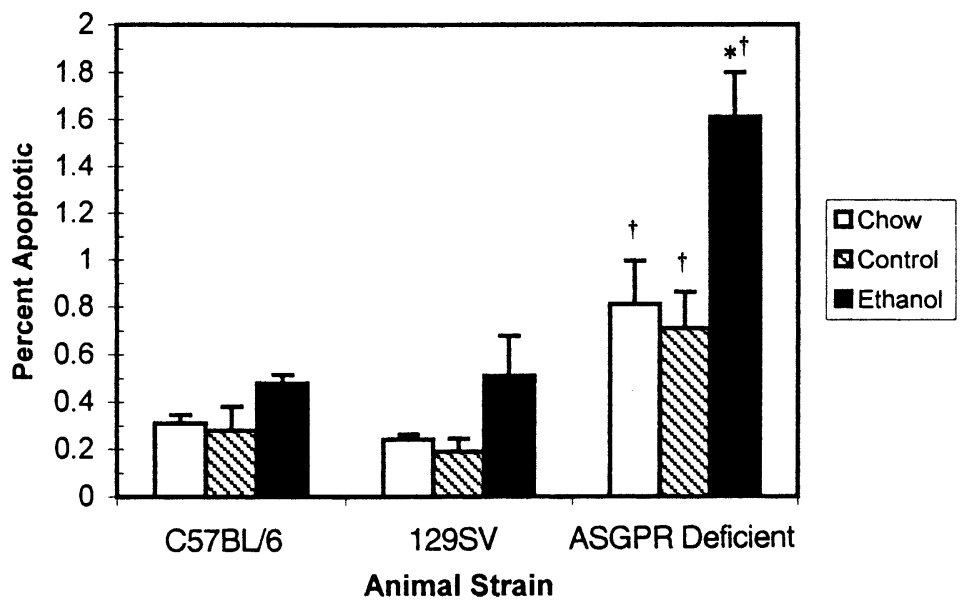

Fig. 5. Comparison, according to animal strain, of TUNEL in livers of animals after ethanol administration. Liver tissue from chow-fed and pair-fed control and ethanol animals was fixed in situ, cryosectioned $(5 \mu \mathrm{m})$, and processed for TUNEL labeling as described in "Section 2." Data are presented as the percent apoptotic (means \pm SEM) of TUNEL positive nuclei or fragments per total cells counted (average of 5500 cells counted per treatment group; $\mathrm{N}=3-$ 5 experiments). Key: $\left(^{*}\right)$ statistically significant, $P \leq 0.05$, when compared to chow and control within the same animal strain, and ( $\dagger$ ) statistically significant, $P \leq 0.05$, when compared to the wild-types, C57BL/6 and $129 \mathrm{SV}$, within the same diet. 
This hypothesis is supported further by data reported in this paper. The labeling indexes for the control groups of the ASGPR-deficient mice exceeded what was observed in the ethanol groups from the wild-type mice. What this suggests to us is that the absence of ASGPR in the deficient mice serves as a sort of "first-hit insult" similar to what is observed with ethanol administration to wild-type animals, which results in impaired receptor function. Ethanol administration to the ASGPR-deficient mice then serves as a "second-hit injury," which results in additional liver damage, similar to what was seen with LPS [25].

Decreased clearance of apoptotic bodies from the liver can by no means account for the entire scope of ethanolinduced apoptosis. Ethanol is clearly affecting some other mechanism(s) that contributes to the elevated levels of apoptosis observed after ethanol administration. The results reported in this paper using TUNEL analysis show an effect of ethanol on the number of apoptotic bodies present in the liver beyond what could be explained by the absence or impairment of functional ASGPR. The effects of ethanol-induced apoptosis in the liver most likely result from a series of multifaceted events. One possibility is that delayed clearance of apoptotic cells leads to stimulation of surrounding non-parenchymal cells, such as Kupffer, hepatic stellate, and liver epithelial cells, to release pro-inflammatory or pro-fibrogenic agents; other potential mechanisms include increased oxidative stress, increased cytokine production, and activation of caspases, particularly caspase-3 [22,26,27]. It is our contention that delayed clearance of apoptotic cells may contribute to the liver injury associated with ethanol consumption.

One purpose of the studies described in this paper was to establish that the effects of ethanol on RME by the ASGPR would be observed with a mouse model. Our results demonstrate that the effects of ethanol on the ASGPR system in mice mimic those previously observed in our laboratory using a rat model. Another purpose was to begin characterization of an ASGPR-deficient mouse model that could be used to study the effects of the receptor on ethanol-induced liver injury. We have shown that the endocytosis of ASOR, a ligand for the ASGPR, is negligible in the deficient mouse strain, and that basal levels of apoptotic bodies in livers of receptor-deficient mice are three times higher than in wild-type mice. These results support the use of the ASGPR-deficient mouse model to study the role of the ASGPR in ethanol-induced liver injury, including ethanol-induced apoptosis, and studies are currently being conducted in our laboratory using the ASGPR-deficient mouse model. The potential of the ASGPR-deficient mouse goes beyond the scope of ethanol-induced liver injury. Although the ASGPR is one of the most widely used models of RME, its physiological role is still unknown. The ASGPR-deficient mouse model should provide an excellent means to study the function of the ASGPR under normal physiological conditions.

\section{Acknowledgments}

This research was supported by Grant AA07846 from the National Institute on Alcohol and Alcohol Abuse, Grant AA07582 from the National Institutes of Health, the Department of Veterans Affairs, and the Alcohol Beverage Medical Research Foundation (ABMRF).

\section{References}

[1] Tuma DJ, Mailliard ME, Casey CA, Volentine GD, Sorrell MF. Ethanol-induced alterations of plasma membrane assembly in the liver. Biochim Biophys Acta 1986;856:571-7.

[2] Casey CA, Sorrell MF, Tuma DJ. Effect of ethanol on asialoglycoprotein receptor function. In: Wu GY, Wu CH, editors. Liver diseases: targeted diagnosis and therapy using specific receptors and ligands. New York: Marcel Dekker; 1991. p. 189-213.

[3] Casey CA, Camacho KB, Tuma DJ. The effects of chronic ethanol administration on the rates of internalization of various ligands during hepatic endocytosis. Biochim Biophys Acta 1992;1134: 96-104.

[4] Tworek BL, Tuma DJ, Casey CA. Decreased binding of asialoglycoproteins to hepatocytes from ethanol-fed rats. Consequence of both impaired synthesis and inactivation of the asialoglycoprotein receptor. J Biol Chem 1996;271:2531-8.

[5] Goldstein JL, Brown MS, Anderson RG, Russell DW, Schneider WJ. Receptor-mediated endocytosis: concepts emerging from the LDL receptor system. Annu Rev Cell Biol 1985;1:1-39.

[6] Casey CA, Kragskow SL, Sorrell MF, Tuma DJ. Chronic ethanol administration impairs the binding and endocytosis of asialoorosomucoid in isolated rat hepatocytes. J Biol Chem 1987;262: 2704-10.

[7] Casey CA, Kragskow SL, Sorrell MF, Tuma DJ. Effect of chronic ethanol administration on total asialoglycoprotein receptor content and intracellular processing of asialoorosomucoid in isolated rat hepatocytes. Biochim Biophys Acta 1990;1052:1-8.

[8] Casey CA, Wiegert RL, Tuma DJ. Chronic ethanol administration impairs ATP-dependent acidification of endosomes in rat liver. Biochem Biophys Res Commun 1993;195:1127-33.

[9] Tworek BL, Wiegert RL, Jeanette II JP, Tuma DJ, Casey CA. Differential effects of monensin on asialoglycoprotein receptor function after short-term ethanol administration. Biochem Pharmacol 1998;55:1603-9.

[10] Tworek BL, Wiegert RL, Tuma DJ, Casey CA. Effects of monensin on ethanol-induced alterations in function of hepatocellular asialoglycoprotein receptor subpopulations. Alcohol Clin Exp Res 1998;22: 97-104.

[11] Goldin RD, Hunt NC, Clark J, Wickramasinghe SN. Apoptotic bodies in a murine model of alcoholic liver disease: reversibility of ethanolinduced changes. J Pathol 1993;171:73-6.

[12] Baroni GS, Marucci L, Benedetti A, Mancini R, Jezequel AM, Orlandi F. Chronic ethanol feeding increases apoptosis and cell proliferation in rat liver. J Hepatol 1994;20:508-13.

[13] Savill JS, Wyllie AH, Henson JE, Walport MJ, Henson PM, Haslett C. Macrophage phagocytosis of aging neutrophils in inflammation. Programmed cell death in the neutrophil leads to its recognition by macrophages. J Clin Invest 1989;83:865-75.

[14] Savill JS, Henson PM, Haslett C. Phagocytosis of aged human neutrophils by macrophages is mediated by a novel "charge-sensitive" recognition mechanism. J Clin Invest 1989;84:1518-27.

[15] Savill J, Dransfield I, Hogg N, Haslett C. Vitronectin receptormediated phagocytosis of cells undergoing apoptosis. Nature 1990; 343:170-3. 
[16] Dini L, Autuori F, Lentini A, Oliverio S, Piacentini M. The clearance of apoptotic cells in the liver is mediated by the asialoglycoprotein receptor. FEBS Lett 1992;296:174-8.

[17] Ashwell G, Harford J. Carbohydrate-specific receptors of the liver. Annu Rev Biochem 1982;51:531-54.

[18] Dini L, Lentini A, Diez GD, Rocha M, Falasca L, Serafino L, VidalVanaclocha F. Phagocytosis of apoptotic bodies by liver endothelial cells. J Cell Sci 1995;108:967-73.

[19] McVicker BL, Casey CA. Ethanol-impaired hepatic protein trafficking: concepts from the asialoglycoprotein receptor system. Clin Biochem 1999;32:557-61.

[20] Oka JA, Weigel PH. Recycling of the asialoglycoprotein receptor in isolated rat hepatocytes. J Biol Chem 1983;258:10253-62.

[21] Van Dyke RW. Effect of cholera toxin and cyclic adenosine monophosphate on fluid-phase endocytosis, distribution, and trafficking of endosomes in rat liver. Hepatology 2000;32:1357-69.

[22] Nanji AA. Apoptosis and alcoholic liver disease. Semin Liver Dis 1998;18:187-90.
[23] Natori S, Rust C, Stadheim LM, Srinivasan A, Burgart LJ, Gores GJ. Hepatocyte apoptosis is a pathologic feature of human alcoholic hepatitis. J Hepatol 2001;34:248-53.

[24] Ziol M, Tepper M, Lohez M, Arcangeli G, Ganne N, Christidis C, Trinchet JC, Beaugrand M, Guillet JG, Guettier C. Clinical and biological relevance of hepatocyte apoptosis in alcoholic hepatitis. J Hepatol 2001;34:254-60.

[25] Deaciuc IV, Nikolova-Karakashian M, Fortunato F, Lee EY, Hill DB, McClain CJ. Apoptosis and dysregulated ceramide metabolism in a murine model of alcohol-enhanced lipopolysaccharide hepatotoxicity. Alcohol Clin Exp Res 2000;24:1557-65.

[26] Mi LJ, Mak KM, Lieber CS. Attenuation of alcohol-induced apoptosis of hepatocytes in rat livers by polyenylphosphatidylcholine (PPC). Alcohol Clin Exp Res 2000;24:207-12.

[27] Zhou Z, Sun X, Kang YJ. Ethanol-induced apoptosis in mouse liver: Fas- and cytochrome $c$-mediated caspase- 3 activation pathway. Am J Pathol 2001;159:329-38. 